\title{
Development and Implementation of Visual Exposure Indicator for Residential Development
}

\author{
KyungJin $\mathrm{An}^{1}$, Hoon $\mathrm{Ko}^{2}$, and ChoongSik Kim ${ }^{3}$ \\ ${ }^{1}$ Department of Environmental Planning, Konkuk University \\ 120 Neungdong-ro, Gwangjin-gu, Seoul, 143-701 South Korea \\ ${ }^{2}$ The Department of Informatics, J. E. Purkinje University, \\ J. E. Purkinje University Faculty of Science, Ceske mladeze 8, \\ 400 96, Usti nad Labem, Czech Republic, \\ ${ }^{3}$ Dept. of Traditional Landscape Architecture, \\ Korea National University of Cultural Heritage, 323-812, Buyeo-gun, Korea \\ ${ }^{1}$ dorian@konkuk.ac.kr, ${ }^{2}$ hoon.ko@ujep.cz, ${ }^{3}$ kimch@nuch.ac.kr
}

\begin{abstract}
.
In recent years, residential tower blocks, residential rights such as a right to enjoy sunshine and good view have become socially sensitive matters. The research aimed to establish a methodology to find out the extent of visual damage and households caused by residential development. The research aims to make a quantitative calculation of visual grading and degree of concealment from residential development. Kumho residential apartment development was selected as a case study. Within the case study, 5 blocks were chosen to simulate which is located between Han River and Dalmaji hill. The degree of visual screening is analysed into three different visual exposures; Visual Exposure, Distance-weighed Visual Exposure and Area-weighed Visual Exposure. Then the Visual Exposures were compared with visual damage and landscape simulations. In particular, Area-weighed Visual Exposure has a great potential to be implemented into planning process including disputes, grant and assessment since it does reflect human visual perceptions.
\end{abstract}

Keyword: Visibility Analysis, 3D Simulation, VE3D, Arcview, Visual Exposure

\section{Introduction}

Within development management process, dealing with visual impact assessment is known to an effective way of evaluating environmental effect for the area of development. The process of visibility analysis also enables planners to identify potential landscape character and its changes. In particular, the visibility analysis based on computer generated media can be effective, intuitive and economic. Recently, within residential tower blocks, residential rights such as a right to enjoy sunshine and good view have become socially sensitive matters. Since visually valuable natural resources are within urban areas such as river and mountain, local planning authorities are concerned about the social rights and attempt to minimise or avoid any possible dispute. For local planning authority's point of view, the visibility issues - for this social reason - become significant in policy making [1,4]. Recently, Visual Density Indicator is used for various statutory legislations for height and density on residential projects. This research develops Visual Indicators which human visual senses were taken into account focusing on small size residential developments [2,3]. The research also assesses the extent of visual damages caused by the development and therefore, the research finding aims to contribute in planning policy establishments. This therefore, aims to develop and implement visual exposure analysis for building proposals in particular residential developments $[8,9,10]$. 
The study also aims to develop visual exposure indicator for planning application in particular residential development. The process of production and accuracy of the analysis are taken into account in comparison with existing methodologies [5, 7]. The study employ a case study in Seoul as a methodology to develop a credible and accurate process of providing visual exposure indicator within urban environment and planning application [5].

This research is divided into five sections. Section 1 introduces the background, research questions, and overall organisation of the study. Section 2 attempts to conceptualise visual exposure indicator and analysis in formal form of planning. It also reviews historical backgrounds and definitions to reach the most appropriate concept of the research. Thereafter, it presents the main points of visual exposure indicator analysis process together with emerging issues of current use of the technology in planning through literature review. Section 3, methodology is divided into two sections with each addressing site selection/viewpoint and research methodology/process. Section 4 deals with findings and results. Finally, section 5 concludes the study with recommendations.

\section{Development of Visual Indicator using 3D Visual Exposure}

\subsection{Developing 3D Visual Exposure}

Visual Exposure quantifies visual opportunities and visual frequency from multiple viewpoints. However, raster dataset based Visual Exposure is not suitable for urban areas where built up structures are dominant. Moreover, simple black and white (visible and not visible) analysis does not reflect visible distance and characteristics of the site [6][8][9]. If Visual Exposure is carried out based on building elevations, the visibility opportunity, grading, and degree of concealment could be calculated. For this analysis, 3D modelling has to be performed based on vector datasets of terrain and buildings. Vector modelling technique is able to represent landscapes in better reality including mesh and surface. Recently, vector modelling programmes are highly advanced; however, vector modelling techniques for Visibility Exposure has not been developed yet.

The calculation of Visibility Exposure is measured from Lines Of Sight (LOS) and whether the LOSs hitting the objects. Consequently, the length of LOS becomes visibility distance and cumulative LOS makes Visibility Exposure map. In order to visualise this process within vector models, Visual Exposure 3D (VE3D) was developed.

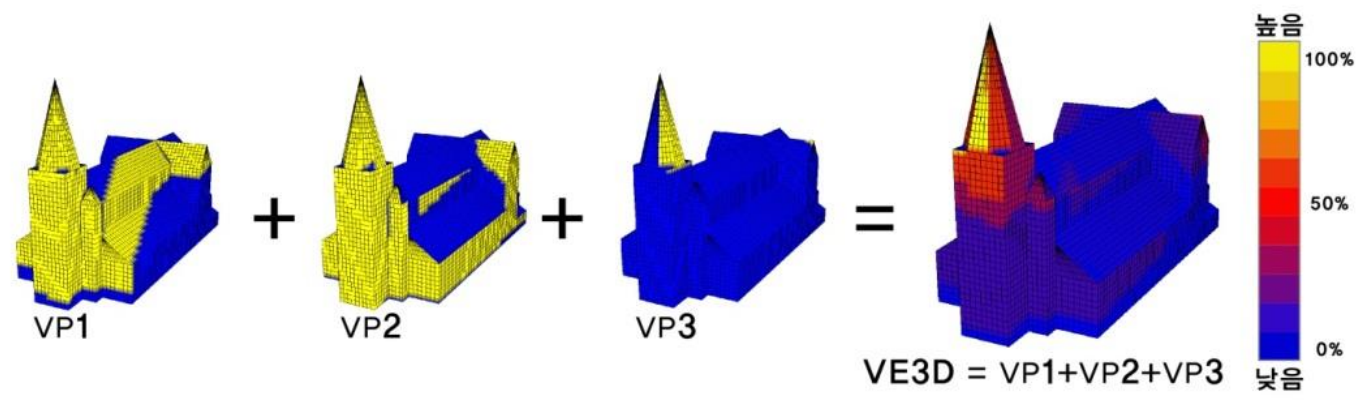

Figure 1. The Process of VE3D

\subsection{Visual Exposure with Human Visual Perception}

Traditionally, Visual Exposure and cumulative visibility map are produced without taking distances into account. However, human perceives visual objects based on distances and as a trade-off, visible objects are inverse proportion to squared distance. Therefore, visible distance and object size need to be considered in order to produce more accurate visible exposure results [Table 1]. 
Table 1. Calculation of Visual Exposure

\begin{tabular}{|l|l|l|}
\hline Vf: Visual Exposure & $\begin{array}{l}\text { Vd: Distance-weighed Visual } \\
\text { Exposure }\end{array}$ & $\begin{array}{l}\text { Va: Area-weighed Visual } \\
\text { Exposure }\end{array}$ \\
\hline$V f=\sum_{i=1}^{m} \sum_{i=1}^{n} V_{i j}$ & $V d=\sum_{i=1}^{m} \sum_{i=1}^{n} \frac{V_{i j}}{D_{i j}}$ & $V a=\sum_{i=1}^{m} \sum_{i=1}^{n} \frac{V_{i j}}{D_{i}^{2}}$ \\
\hline $\begin{array}{l}\text { i: viewpoints on the building (m number), j: view objectives (n number), Vij: visibility (visible=0, invisible=1), Dij: } \\
\text { distance between building (i) and view objects (j) }\end{array}$
\end{tabular}

\section{Methodology}

The research aims to make a quantitative calculation of visual grading and degree of concealment from residential development. Kumho residential apartment development was selected as a case study. Within the case study, 5 blocks were chosen to simulate which is located between Han River and Dalmaji hill. 10 thresholds of visual grading were classified based on Visual Exposure. Single residential block was also divided with $3 \mathrm{~m}$ grids for use in individual households' Visual Exposure. Total 36 viewpoints were chosen to assess visible and not visible status and size/distance were considered as in $600 \mathrm{~m}, 1000 \mathrm{~m}$, and $1800 \mathrm{~m} .36$ grids $(200 \mathrm{~m} \times 200 \mathrm{~m})$ were created which include near distance 5 , mid distance 11 , and long distance 20 from the centre point.

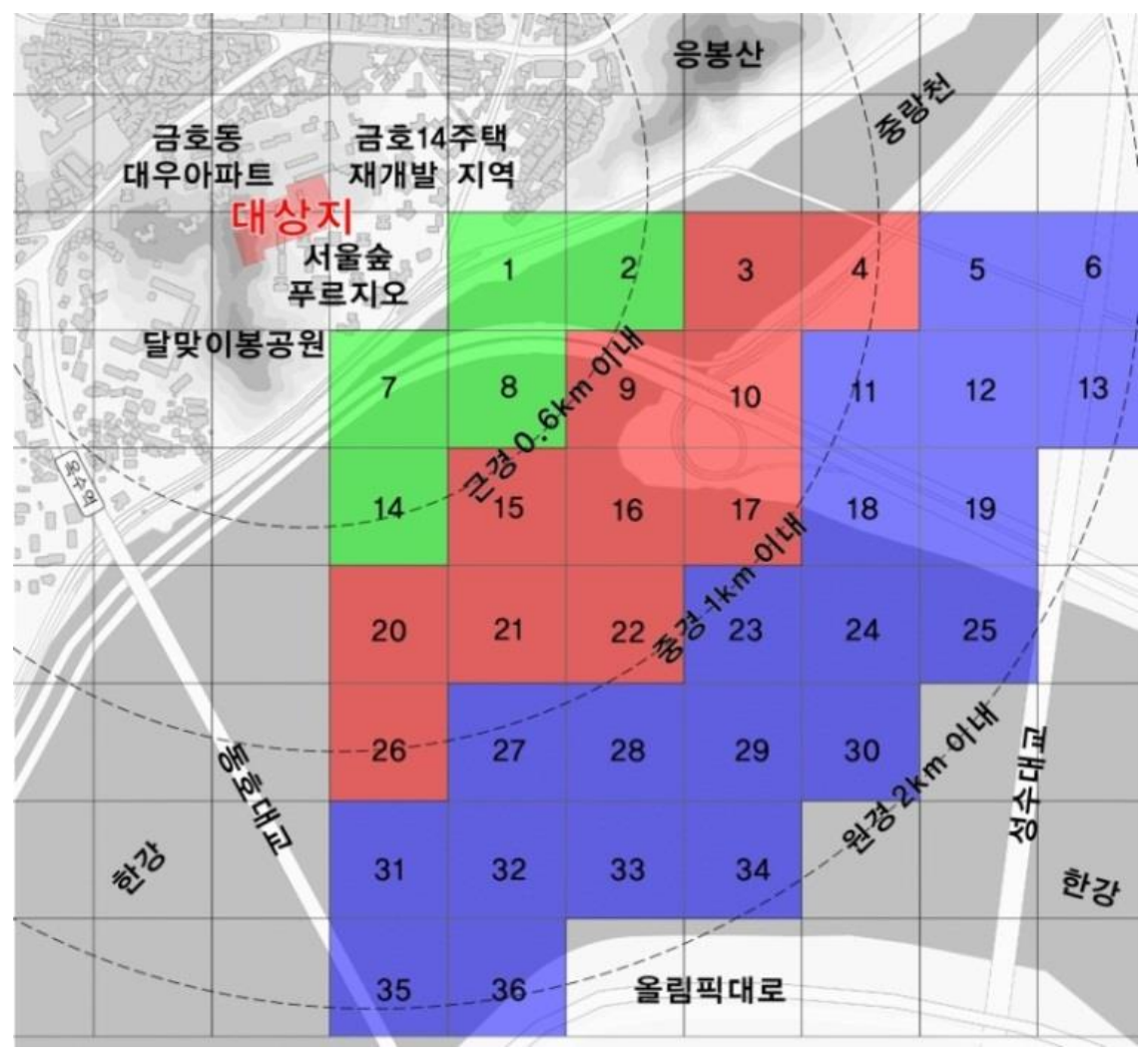

Figure 2. Grid Methodology 


\section{Research Results}

\subsection{Efficiency on Producing Visibility Analysis}

The analysis models were created with Rhinoceros 5.0 in particular, NURBS were used for terrains and surface was implemented for buildings and other built up structures. For Visual Exposure analysis, VE3D were utilised. The system was Windows 7, Intel Core i7 950 3.07GHz CUP, 12GB DDR3 RAM, Nvidia GeForce GTx 460, 7200rpm Sata HDD. For instance, 134463 surfaces were calculated for façade of 7 residential blocks from a single viewpoint and it took 8 minutes 10 seconds. The more invisible surfaces increase, the quicker calculations were made. This result indicates that it could be common practice to carry out 3D Visual Exposure analysis using 3D models in urban landscape.

In order to check accuracy of the process viewpoint no 8 was exemplified for comparison of before, after, simulation, visual areas and VE3D. According to the perspectives, from the viewpoint no 8, lower levels of 113/ 114 blocks and mid levels of 201-203 blocks can be visible. This is the same results with VE3D analysis. After the new residential blocks, only from mid levels of 202 and 203 blocks viewpoint no 8 was visible. The research compared visibility before and after new residential blocks, then mid and lower levels of 7 blocks were visually affected. Meanwhile, VE3D results were matching with computerised landscape simulation; therefore, the results from visibility analysis by VE3D are credible. Moreover, VE3D would be effective for visibility comparisons of visual damage on highly valuable landmarks and assessing the extent of the damage [Table 2].

Table 2. VE3D Visibility Comparison (Viewpoint No 8)

\begin{tabular}{|c|c|c|c|}
\hline \multicolumn{2}{|c|}{ Landscape Simulation } & \multicolumn{2}{c|}{ VE3D Analysis } \\
\hline $\begin{array}{c}\text { Before the New } \\
\text { Residential Blocks }\end{array}$ & $\begin{array}{c}\text { After the New } \\
\text { Residential Blocks }\end{array}$ & $\begin{array}{c}\text { Before the New } \\
\text { Residential Blocks }\end{array}$ & $\begin{array}{c}\text { After the New } \\
\text { Residential Blocks }\end{array}$ \\
\hline
\end{tabular}

\subsection{Visual Indicator Comparison}

Visibility maps were produced from 36 viewpoints and then, using the formula [Figure 3], Visual Exposure (Vf), Distance-weighed Visual Exposure (Vd), and Area-weighed Visual Exposure (Va) were made. Each visual exposure was standardised as 10 grading system. Before the new residential blocks, grade 10 (maximum) was scored in most of block no 113 - no 203 in Vf, high/mid levels of no 203 in Vd and mid/low levels of no 203 in Va. 


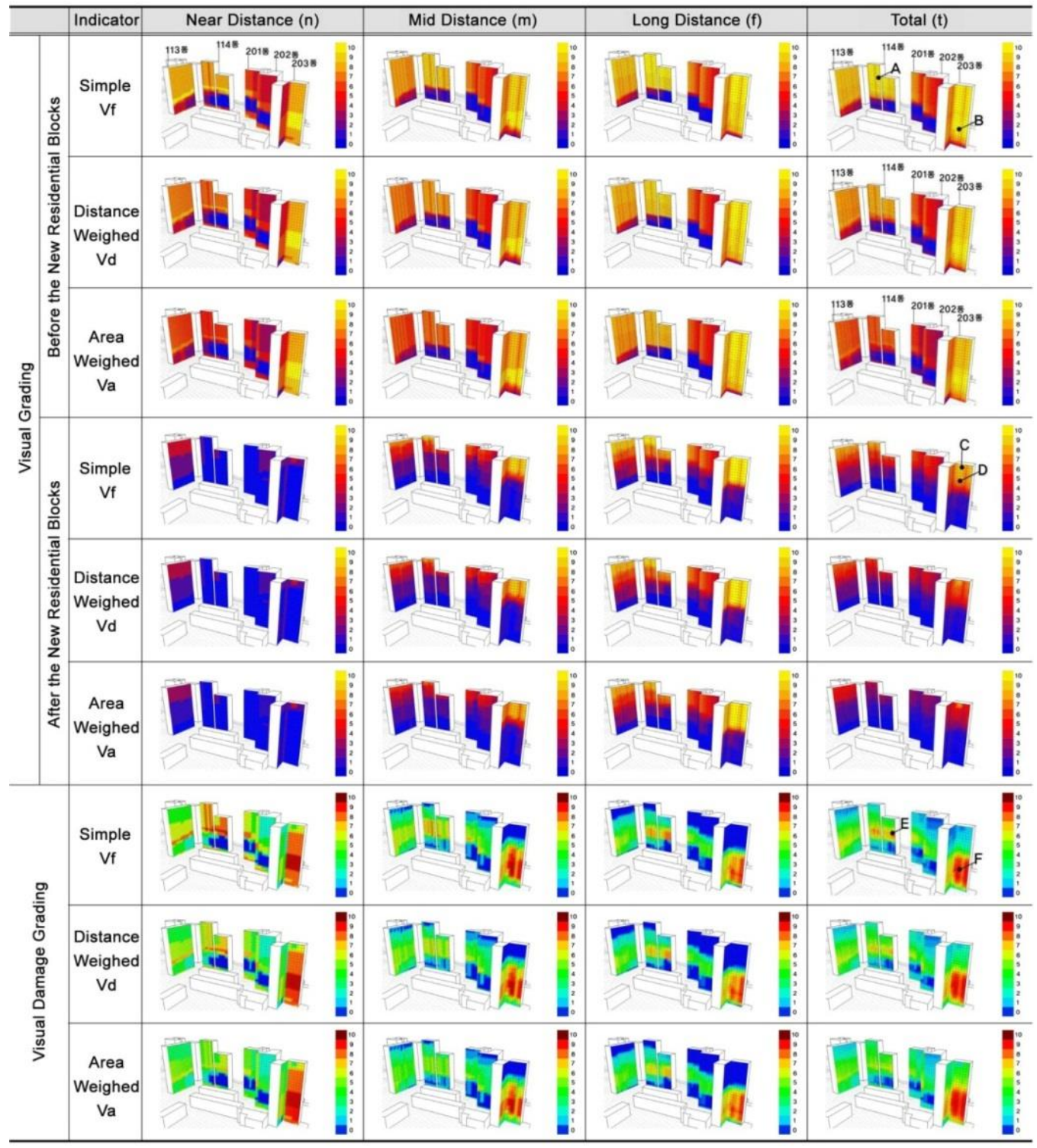

Figure 3. Visual Exposure Results

The produced visual indicators were cross checked with computerised simulations for accuracy and credibility.
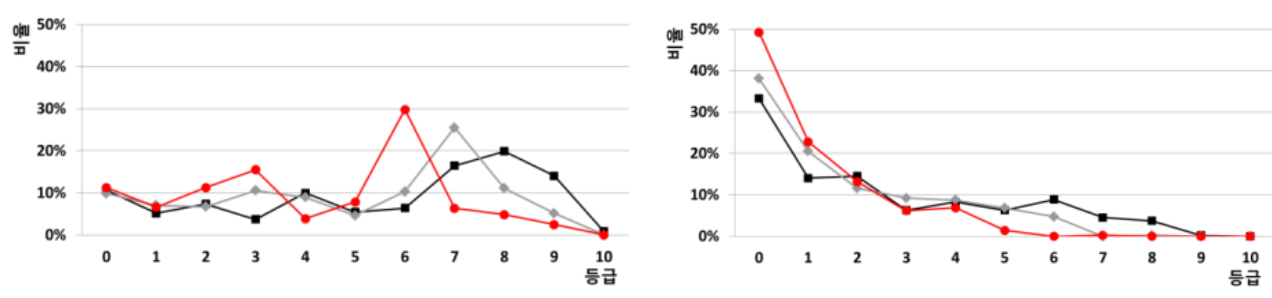

Figure 4. Visual Indicators before/after the New Residential Blocks

Based on Figure 3 and 4, there are some discrepancies between Vf and Va due to the area differences. Accordingly, the results illustrated the areas of high value in Va have more visual damages [Figure 5]. 
(A)
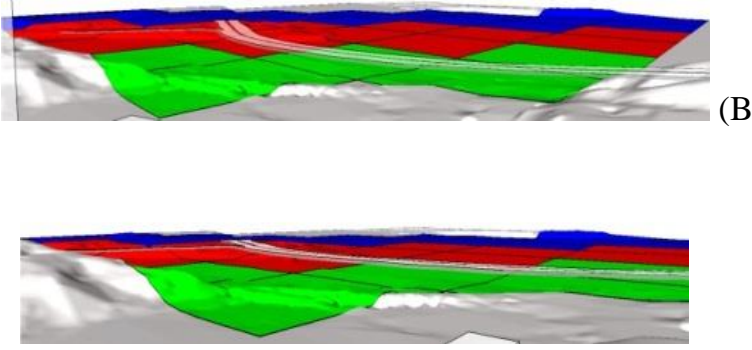

(C)

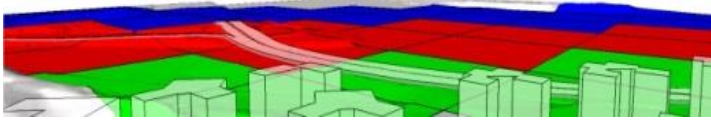

(E)
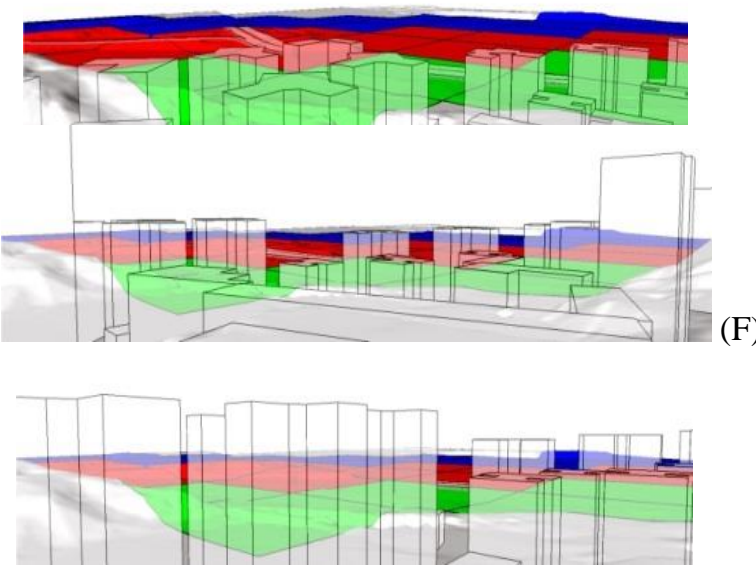

Figure 5. Locations A, B, C, D, E and F (Green-Near Distance, Red-Mid Distance, Blue-Long Distance)

\subsection{Visual Indicator Analysis on Residential Tower Block}

The research introduced $3 \times 3 \mathrm{~m}$ grid which represents single household within residential tower blocks. Total of 7 tower blocks were applied and 1728 viewpoints were accordingly created. During the process, the majority grids in Vf fell into grade 7-9, in Vd most of grids were grade 7 and grade 6 as well as 2 and 3 were mostly appeared in Va. After new residential blocks were constructed, grade 9 and 10 would be disappeared in Vf; whereas, grade 1-8 remained same. Moreover, grade 0 was increased from $10.7 \%$ to $33.3 \%$, which lead into increase of visual screening as $22.6 \%$. However, grade 0 in $\mathrm{Va}$ increased from $11.3 \%$ to $49.2 \%$ which indicated nearly half of balcony of the households were screened. In addition, view towards Han River was sharply blocked since grade 6 10 were disappeared [Table 3]. 
Table 3. Visual Indicator (per area, \%)

\begin{tabular}{|c|c|c|c|c|c|c|c|c|c|c|c|c|}
\hline Landscape & Indicator Grade & $\mathbf{0}$ & 1 & 2 & 3 & 4 & 5 & 6 & 7 & 8 & 9 & 10 \\
\hline \multirow{3}{*}{$\begin{array}{c}\text { Before New } \\
\text { Residential } \\
\text { Blocks }\end{array}$} & $\mathrm{Vf}$ & 10.7 & 5.2 & 7.3 & 3.7 & 10.0 & 5.4 & 6.4 & 16.4 & 19.9 & 14.1 & 0.8 \\
\hline & $\mathrm{Vd}$ & 9.9 & 7.1 & 6.7 & 10.6 & 9.0 & 4.6 & 10.3 & 25.5 & 11.1 & 5.2 & 0.1 \\
\hline & Va & 11.3 & 6.6 & 11.3 & 15.5 & 3.9 & 7.9 & 29.8 & 6.4 & 4.9 & 2.5 & 0.1 \\
\hline \multirow{3}{*}{$\begin{array}{l}\text { After New } \\
\text { Residential } \\
\text { Blocks }\end{array}$} & $\mathrm{Vf}$ & 33.3 & 14.1 & 14.5 & 6.3 & 8.3 & 6.3 & 8.9 & 4.5 & 3.7 & 0.2 & - \\
\hline & $\mathrm{Vd}$ & 38.1 & 20.5 & 11.6 & 9.3 & 8.7 & 6.8 & 4.7 & - & 0.2 & - & - \\
\hline & Va & 49.2 & 22.8 & 13.2 & 6.2 & 6.9 & 1.4 & - & 0.2 & - & - & - \\
\hline
\end{tabular}

Residential tower blocks which contained 552 households were included for the case study. A large number of grades 7, 9 and 10 were appeared in Vf in before new residential blocks were constructed. Grade 8 is in majority in $\mathrm{Vd}$; whereas, grade 4, 6, 7, 9 were dominant in Va. However, there were no grade $6-10$ in $\mathrm{Va}$ in after new residential blocks were constructed. Grade 0 increase $600-800 \%$ in Vf, Vd and Va which means view to Han River would be screened dramatically. For visual damage, grade 0 increased from $3.3 \%$ to $23.2 \%$ in Vf, which indicated $19.9 \%$ of the households were blocked the view towards Han River. However, according to Va results grade 0 increased from $4.5 \%$ to $29 \%$ and households which were blocked views from Han River was 24.5\% [Table 4].

Table 4. Visual Damage (households)

\begin{tabular}{|c|c|c|c|c|c|c|c|c|c|c|c|c|c|}
\hline \multicolumn{2}{|c|}{ Landscape } & Indjicator & $\mathbf{0}$ & 1 & 2 & 3 & 4 & 5 & 6 & 7 & 8 & 9 & 10 \\
\hline \multirow{6}{*}{$\begin{array}{l}\text { Visual } \\
\text { Grading }\end{array}$} & \multirow{3}{*}{$\begin{array}{c}\text { Before New } \\
\text { Residential } \\
\text { Blocks }\end{array}$} & $\mathrm{Vf}$ & 18 & 54 & 20 & 29 & 25 & 54 & 49 & 65 & 40 & 107 & 91 \\
\hline & & $\mathrm{Vd}$ & 17 & 41 & 38 & 38 & 41 & 70 & 32 & 72 & 121 & 52 & 30 \\
\hline & & Va & 25 & 38 & 46 & 63 & 88 & 25 & 74 & 104 & 1 & 75 & 13 \\
\hline & \multirow{3}{*}{$\begin{array}{c}\text { After New } \\
\text { Residential } \\
\text { Blocks }\end{array}$} & $\mathrm{Vf}$ & 128 & 97 & 57 & 66 & 32 & 59 & 42 & 28 & 29 & 14 & 0 \\
\hline & & $\mathrm{Vd}$ & 149 & 105 & 83 & 59 & 68 & 33 & 28 & 23 & 4 & 0 & 0 \\
\hline & & $\mathrm{Va}$ & 160 & 164 & 96 & 66 & 34 & 28 & 0 & 4 & 0 & 0 & 0 \\
\hline \multirow{3}{*}{\multicolumn{2}{|c|}{ Visual Damage }} & $\mathrm{Vf}$ & 30 & 140 & 58 & 67 & 56 & 67 & 49 & 34 & 21 & 30 & 0 \\
\hline & & $\mathrm{Vd}$ & 17 & 93 & 93 & 88 & 78 & 59 & 55 & 25 & 13 & 31 & 0 \\
\hline & & Va & 22 & 77 & 97 & 88 & 91 & 70 & 43 & 17 & 10 & 37 & 0 \\
\hline
\end{tabular}




\section{Conclusion}

One of planning issues in recent years is visually valuable natural resources are within urban areas such as river and mountain, local planning authorities are concerned about the social rights and attempt to minimise or avoid any possible dispute. For that reason, within many planning application processes, Visual Density Indicator is used for various statutory legislations for height and density on residential projects. This research develops Visual Indicators which human visual senses were taken into account focusing on small size residential developments. The research also assesses the extent of visual damages caused by the development and therefore, the research finding aims to contribute in planning policy establishments. This therefore, aims to develop and implement visual exposure analysis for building proposals in particular residential developments.

The research also aimed to establish a methodology to find out the extent of visual damage and households caused by residential development. Visual exposure programme which developed in the research can be run in Windows based computers and have large potential to be implemented in common development practice. Moreover, the degree of visual screening is analysed into three different visual exposures; Visual Exposure, Distance-weighed Visual Exposure and Area-weighed Visual Exposure. Then the Visual Exposures were compared with visual damage and landscape simulations. In particular, Area-weighed Visual Exposure has a great potential to be implemented into planning process including disputes, grant and assessment since it does reflect human visual perceptions.

\section{Acknowledgement}

This work was supported by National Research Foundation of Korea - Grant funded by the Korean Government (Ministry of Science, ICT and Future Planning)-(NRF-2013-K1A3A1A39075091).

\section{References}

[1] P. C. Anastasopoulos, M. B. Islam, D. Perperidou and M. G. Karlaftis, "Hazard-Based Analysis of Travel Distance in Urban Environments: Longitudinal Data Approach", Journal of Urban Planning and Developmet-ASCE, vol. 138, no. 1, (2012), pp. 53-61.

[2] Z. Zheng and Z. Bohong, "Study on Spatial Structure of Yangtze River Delta Urban Agglomeration and Its Effects on Urban and Rural Regions", Journal of Urban Planning and Development-ASCE, vol. 138, no. 1, (2012), pp. 78-89.

[3] D. K. Lee and H. Y. Choe, "Estimating the Impacts of Urban Expansion on Landscape Ecology: Forestland Perspective in the Greater Seoul Metropolitan Area", Journal of Urban Planning and Development-ASCE, vol. 137, no. 4, (2011), pp. 425-437.

[4] A. T. M. Oakil, D. Ettema, T. Arentze and H. Timmermans, "Longitudinal Model of Longer-Term Mobility Decisions: Framework and First Empirical Tests", Journal of Urban Planning and Development-ASCE, vol. 137, no. 3, (2011), pp. 220-229.

[5] E. C. M. Hui, I. M. H. Ng and K.K. Lo, "Analysis of the Viability of an Urban Renewal Project under a Risk-Based Option Pricing Framework", Journal of Urban Planning and Development -ASCE, vol. 137, no. 2, (2011), pp. 101-111.

[6] B. J. Park, K. Furuya, T. Kasetani, N. Takayama, T. Kagawa and Y. Miyazaki, "Relationship between psychological responses and physical environments in forest settings", Landscape and Urban Planning, vol. 102, no. 1, (2011), pp. 24-32.

[7] J. B. Kirkpatrick, G. D. Daniels and A. Davison, "Temporal and spatial variation in garden and street trees in six eastern Australian cities", Landscape and Urban Planning, vol. 1021, no. 3, (2011), pp. 244252.

[8] J. M. D. Santos, R. F. de Villarán, Í. R. Arrarás, E. C. P. de Provens, "The visual exposure in forest and rural landscapes: An algorithm and a GIS tool", Landscape and Urban Planning, vol. 101, no. 1, (2011), pp. 52-58.

[9] G. Domon, "Landscape as resource: Consequences, challenges and opportunities for rural development", Landscape and Urban Planning, vol. 100, no. 1, (2011), pp. 338-340.

[10] A. Jorgensen, "Beyond the view: Future directions in landscape aesthetics research", Landscape and Urban Planning, vol. 100, no. 1, (2011), pp. 353-355. 


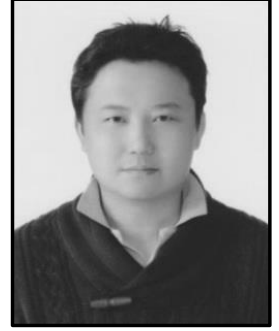

Kyung Jin An, Kyung Jin received BSc in landscape architecture from University of Seoul, South Korea. In 2002, he completed Master of Landscape Architecture in Newcastle University in the UK with Golden Jubilee Award. During the period between 2002 and 2012, he read $\mathrm{PhD}$ in School of Architecture, Planning and Landscape with scholarships from Newcastle University. $\mathrm{He}$ is particularly interested in computer visualisation and its implementation into design industry. He has published a number of papers in the field and continues to research on the same subject. Now, he is an assistant professor at Konkuk University since 2013.

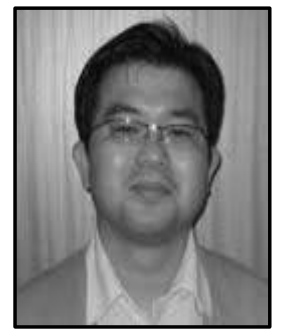

Hoon Ko, He got the B.S. degree in computer science from Howon University, Kunsan-City, S. Korea, in 1998, and M.S. degree in computer science from Soongsil University, Seoul, S. Korea in 2000 and $\mathrm{Ph}$ D. degree in 2004. He had joined in Daejin University as visiting professor from 2002 to 2006. He had worked at Information \& Communications University (ICU), Korea Advanced Institute of Science and Technology (KAIST) in 2007. Next, he had worked at GECAD, ISEP, IPP in Porto, Portugal as a Doctor Researcher from 2008 to 2013. Now he is a research professor at the department of informatics, University of J. E. Purkinje since 2013. $\mathrm{He}$ is interested to Urban Computing Security, Ubiquitous Computing Security, AmI Security, Context-Aware Security, MSEC(Multicast Security), RFID Security, Home Network Security, etc.

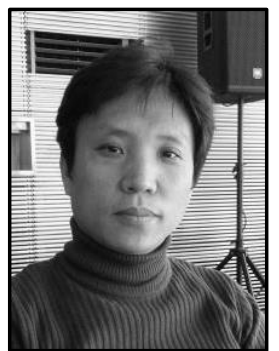

Choong Sik Kim, He received the Bachelor's degree, Master's degree and $\mathrm{Ph}$. D. in Landscape Architecture from The University of Seoul, Seoul, Korea, in 1995, 1998 and 2004 respectively. He has previously worked at Kangnueng-Wonju National University, Kangwondo as an associate professor from 2007 to 2013. He is an assistant professor of the Department of Traditional Landscape Architecture in Korea National University of Cultural Heritage. His research interests lie in the area of quantitative landscape analysis especially in cumulative visibility. 
International Journal of Smart Home

Vol. 9, No. 2 (2015) 